Jurnal Semarak,Vol.4,No.1,Februari 2021, Hal (23-40)

@Prodi Manajemen Fakultas Ekonomi Universitas Pamulang

\title{
PENGARUH LINGKUNGAN DAN PENGALAMAN KERJA TERHADAP KINERJA KARYAWAN PT. MORILLO INTERNASIONAL INDONESIA JAKARTA
}

\author{
Ahmad Maulana Irfanudin \\ Staf Pengajar Fakultas Ekonomi Universitas Pamulang \\ dosen unpam, email : dosen01868@unpam.ac.id
}

\begin{abstract}
ABSTRAK
Penelitian ini bertujuan untuk mengetahui pengaruh Lingkungan kerja dan Pengalaman kerja terhạdap Kinerja Karyawạn. Obyek penelitian yakni para karyawan PT.Morillo Internasional Indonesia. Metode Penelitian secara kuantitatif dengan menguji sampel 55 karyawạn sebagại responden. Analisis data yang digunakan adalah analisis regresi, uji asumsi klasik, uji hipotesis dan koefisien determinasi. Hasil penelitian ini menunjukkan bahwa variabel Lingkungan kerja dan Pengalaman kerja berpengaruh terhadap Kinerja karyawan PT. Morillo Internasional Indonesia secara parsial dan simultan dengan diperoleh dari pengujian secara parsial yaitu dengan uji t variabel Lingkungan kerjạ $\left(\mathrm{X}_{1}\right)$ terhạdap Kinerja $(\mathrm{Y})$ yaitu 3,414 lebih besar dari nilai t-tabel sebesar 1,960 dan nilai signifikan variabel Lingkungan kerja 0,001 atau lebih kecil dari 0,05 , maka dapat dinyatakan bahwa Lingkungan kerja berpengaruh terhadap Kinerja karyawan. Dan uji t variabel Pengalaman $\left(\mathrm{X}_{2}\right)$ terhadap Kinerja Kryawan $(\mathrm{Y})$ yaitu 3,326 lebih besar dari nilai t-tabel 1,960 dan nilai signifikan dari variabel Lingkungan kerja 0,002 atau lebih kecil dari 0,05, karenanya dapat diketahui bersama bahwa $\mathrm{X}_{2}$ berpengaruh terhadap $\mathrm{Y}$. Nilai $F_{\text {hitung }}$ adalah 20,290 yang lebih besar daripada $F_{\text {tabel }} 2,69$, serta nilai taraf signifikansi 0,000 dimana lebih kecil dari 0,05 maka $\mathrm{H}_{\mathrm{o}}$ ditolak dan $\mathrm{H}_{\mathrm{a}}$ diterima, maka dapat di artikan Lingkungan kerja $\left(X_{1}\right)$ dan Pengalaman kerjạ $\left(X_{2}\right)$ secara simulltan berpengaruh terhadap Kinerja karyawan (Y).
\end{abstract}

Kata kunci: Lingkungan, Pengalaman, Kinerja

\section{ABSTRACT}

This research aims to knows the influence of work environment and work experience on employee work performance. The object of this research is the employees of PT. Morillo Internasional Indonesia. The research method was carried out quantitatively by testing a sample of 55 employees as respondents. The data analysis used is regression analysis, classic assumption test, hypothesis test and determination coefficient. The results of this study indicate that the variables work environment and work experience affect the performance of employees of PT. Morillo International Indonesia partially and simultaneously by obtaining from testing partially, namely the t-test for the work environment variable $\left(X_{1}\right)$ on performance $(Y), 3.414$ whichis greater than the t-table value of 1.960 and the significant value of the work environment variable is 0.001 or less than 0.05 , it can be stated that the work environment affects employee performance. And the t test of the Experience variable $\left(X_{2}\right)$ on Employee's performance $(Y)$ is 3.326, whichis greater than the t-table (1.960) and the significant value of the work environment variable is 0.002 or less than 0.05 , it can be stated that experience has an

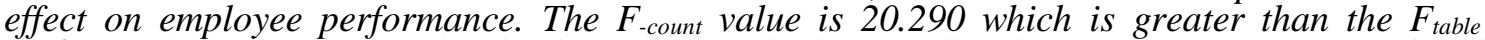
(2.69), and the significance level value is 0.000 which is smaller than 0.05, so $H_{o}$ is rejected and $H_{a}$ is accepted, it can be interpreted that work environment (X1) and work experience (X2) simultaneously has an effect on employee performance $(Y)$.

Keywords: Environment, Experience, Performance

\section{PENDAhUluAN}

A. Latar Belakang 

dicanangkan yang biasanya berlaku secara

Organisasi atau perusahaan selalu memprioritaskan kinerja karyawan yang baik agar dapat menghasilkan kinerja yang optimal juga bagi perusahaan. Menjadi tantangan bagi perusahaan untuk mempertahankan kinerja karyawannya karena keberhasilan atau pencapaian manajemen berdasarkan pada kualitas sumber daya manusia yang dimiliki perusahaan.

Keberlangsungan Perusahan dtentukan oleh kinerja karyawannya, dengan ktaa lain, semakin efektif sumber daya mansuia maka semakin efektif perusahaan.

Ketika karyawan berada di suatu tempat dan melakukan aktifitasnya sewajarnya seorang karyawan dalam bekerja, berhubungan dengan sesame karyawan maupun atasan, maka dikatakan ia berada dalam suatu Lingkungan kerja.

Hal-hal yang dapat mengukur Lingkungan kerja dapat dijelaskan melalui beberapa turunan-komponen nya, yang diantaranya adalah lingkungan manusia, organisasi, maupun lingkungan teknologi.

Lingkungan kerja yang baik akan membentuk suatu culture dan bakal memengaruhi juga kinerja karyawan sehingga mempengaruhi optimal nya perusahaan.

Menurut Robbins (2015), Kinerja karyawan didefinisikan sebagai output pencapaian karyawan dalam pekerjaannya apakah sesuai dengan kriteria yang spesifik tergantung apa jenis pekerjaannya.

Kinerja karyawan didefinisikan sebagai output pencapaian karyawan dalam pekerjaannya apakah sesuai dengan kriteria yang dicanangkan yang biasanya berlaku secara spesifik tergantung apa jenis pekerjaannya.

Menurut Foster (2015:40) menyatakan bahwa Pngalaman kerja diartikan sebagai tolak ukur dan durasi lama kerja serta masa kerja yang di alami oleh karyawan, dan pemahaman atas tugas, hak-hak dan tanggung jawab nya dengan baik.

Berbekal Pengalaman tersebut setiap kryawan dharapkan dapat meningkatkan kwalitas sumber daya manusianya masing-masing.

Menurut Siiagian (2016), Lingkungan kerja bermanfaat untuk menciptakan passion kerja, hingga meningkatkan produktifitas dan prestasi kinerja karyawan.

Dari pernyataan diatas dapat diambil kesimpulan bahwa Lingkungan kerja ialah unsur-unsur terkait pekerjaan yang mempengaruhi kinerja karyawan, mulai dari passion, produktifitas, hingga prestasi kerja karyawan sehingga memberikan dampak terhadap perusahaan.

Tabel 1 Fasilitas dan Prasarana 
Jurnal Semarak,Vol.4,No.1,Februari 2021, Hal (23-40)

@ Prodi Manajemen Fakultas Ekonomi Universitas Pamulang

\begin{tabular}{|c|c|c|c|c|}
\hline No & Easilitas & Qtx & Berfungs & noulkan permasalanan ac \\
\hline 1 & $\mathrm{AC}$ & 5 & 2 & pencaparan \\
\hline 2 & Komputer & 6 & 4 & Kinerja yang menurun \\
\hline 3 & Printer & 4 & 3 & \\
\hline 4 & Mobil & 1 & 1 & Pengalaman baru, akibat nya hasil Kinerja \\
\hline 5 & Alat ukur & 2 & 2 & nva vano belum ontimal Diduoa \\
\hline 6 & Infokus & 4 & 1 & nya yang berum opumal. Diauga \\
\hline & Total & 22 & 13 & kurangnya \\
\hline
\end{tabular}

Pegnalaman adalah salah satu dari banyak faktor yang memengaruhi performa atau kineja karyawan. Semakin banyak jam terbang karyawan diiringi dengan berkembangnya pengalaman yang dimiliki untuk penyelesaian masalah.

Tabel 2 Pengalaman dan Kinerja

Karyawan

\begin{tabular}{|c|c|c|c|}
\hline Indikator & $\begin{array}{l}\text { Ketentuan } \\
\text { Perusahaan }\end{array}$ & Keterangan & Hasil assessment \\
\hline $\begin{array}{l}\text { 1. Lama waktu/ masa } \\
\text { kerja } \\
\text { 2. Tingkat } \\
\text { pengetahuan dan } \\
\text { keterampilan yang } \\
\text { dimiliki } \\
\text { 3. Penguasaan } \\
\text { terhadap pekerjaan } \\
\text { dan Peralatan }\end{array}$ & \begin{tabular}{|l|} 
Standar \\
perusahaan \\
Minimal 1 tahun \\
pengalaman
\end{tabular} & 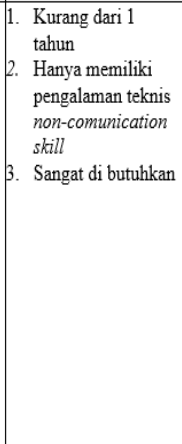 & \begin{tabular}{|l} 
1. Kinerja kurang \\
optimal akibat \\
kurangnya \\
pengalaman/ fresh \\
gruaduate \\
2. Komunikasi antar \\
sesama atasan dan \\
rekan kerja kurang \\
baik/jelek \\
3. Di PT Morillo \\
kurangnya sdm \\
yang mahir / \\
menguasai \\
pekerjaan karena \\
berlatar pengalaman \\
kerja yang berbeda \\
dari sebelum nya
\end{tabular} \\
\hline
\end{tabular}

Berdasarkan Tabel 2 tampak bahwa Pengalaman kerja PT Morillo Internasional Indonesia sangat minim dibutuhkan orang yang berPengalaman di bidang tsersebut sehingga yang kurang dari 1 tahun masih di butuhkan.

Hal tersebut terlihat pada perbandingan antara lama kerja dan penguasaan terhadap alat dan kandidat yang mau belajar di bidang baru maka dari
Kinerja karyawan menjadi tolak ukur keberhasilan karyawan. Kinerja dikonsepkan sbagai perilaku karyawan dlam menetapkan tujuan kerja. Pencapaian target kerja, culture dalam bekerja, termasuk didalamnya pribadi karyawan trsebut.

Tabel 3. Rekapitulasi Laporan Kinerja PT Morillo

\begin{tabular}{|c|c|c|c|c|c|}
\hline Tahun & $\begin{array}{c}\text { Target } \\
\text { Produksi } \\
\text { anti bocor }\end{array}$ & $\begin{array}{c}\text { Realisasi } \\
\text { Produksi }\end{array}$ & $\begin{array}{c}\text { Ketercapaian } \\
\text { Target(\%) }\end{array}$ & $\begin{array}{c}\text { Jumlah hasil } \\
\text { Pemasangan } \\
\text { anti bocor }\end{array}$ & $\%$ \\
\hline 2015 & 300 Roll & 235 Roll & $86.66 \%$ & 200 Rumah & $13.33 \%$ \\
\hline 2016 & 315 Roll & 280 Roll & $80.57 \%$ & 340 Rumah & $19.42 \%$ \\
\hline 2017 & 490 Roll & 390 Roll & $78.94 \%$ & 400 Rumah & $21.05 \%$ \\
\hline 2018 & 600 Roll & 510 Roll & $78.57 \%$ & 450 Rumah & $21.42 \%$ \\
\hline 2019 & 1000 Roll & 840 Roll & $76.66 \%$ & 560 Rumah & $23.33 \%$ \\
\hline
\end{tabular}

Melihat tabel 3, terjadi pnurunan jumlah ketercapaian target dan produksi material, sehingga memengaruhi KPI kinerja PT Morillo secara keseluruhan.

Performance atau kinerja oleh Sedarmayanti (2015) diartikan sebagai hasil kerja yang harus dapat menunjukkan bukti konkrit dan terukur oleh perusahaan tempat karyawan bekerja.

Beberapa masalah menyangkut Kinerja di Morillo internasional jakarta adalah menurunnya tingkat Kinerja yang disebabkan kurang optimalnya penerapan sikap kepemimpinan dan kondisi Lingkungan kerja yang kurang nyaman 
serta sirkulasi udara diruang kerja yang masih rendah dan tidak berfungsi secara normal sehingga Kinerja kurang maksimal dan membuat karyawan tidak nyaman dengan lingkungan kerjanya.

Dilihat dari indikator Kinerja menurut Mangkunegara (2015:75) keadaan di PT Morillo Internasional Indonesia sudah optimal dari segi kualitas karyawan sudah berupaya maksimal untuk menghasilkan kinerja yang sesuai target. Namun dari segi kuantitas kerja dinilai kurrang efektif.

Hal tersebut diakibatkan oleh kurang nyaman dan fasilitas yang kurang dalam segi sirkulasi udara. Dari segi pelaksanaan tugas, dan tanggung jawab juga masih terhambat karena sikap kepemimpinan belum optimal dalam penganbillan keputusan sehingga Kinerja karyawan menjadi menurun.

Berdasarkan hasil penelitian di PT. Morillo terlihat bahwa pencahayaan di setiap ruangan masih kurang terang, ruang geraknya pun masih terbatas, dikarenakan ruangannya yang kurang begitu luas.

Serta Pengalaman kerja karyawan yang kebanyakan dari 1-2 tahun saja bekerja. Atas dasar penjelasan yang dijabarkan sebelumnya, penulis berminatt untuk mengambil pneelitian yang bertajuk "Pengaruh Lingkungan dan Pengalaman Kerja Terhadap Kinerja Karyawan PT. Morillo Internasional Indonesia Jakarta”.

\section{B. Rumusan Masalah.}

sebelumnya, penulis mencatat perumusan masalah dibawah ini:

1. Adakah pengạruh LingkunganKerja (LK) terhạdap KinerjaKaryawan (KK) di PT. Morillo Internasional Indonesia?

2. Adakah pengạruh $\mathrm{PK}$ terhạdap $\mathrm{KK}$ di PT. Morillo Internasional Indonesia?

3. Adakah Pengaruh LK dan PK secara bersama-sama terhadap KK di PT. Morillo Internasional Indonesia?

\section{Tujuan Penelitian}

Setelah dibuat perumusan masalah dan analisa yang dijabarkan sebelumnya, pnelitian bertujuan:

1. Untuk mengetahui besar pengaruh LingkunganKerja (LK) terhạdap KinerjaKaryawan (KK) pada PT. Morillo Internasional Indonesia.

2. Untuk mengetahui besar pengaruh PengalamanKerja (PK) terhạdap KK pada PT. Morillo Internasional Indonesia.

3. Untuk mengetahui seberapa besar pengaruh LK dan PK secara simultan terhadap KK pada PT Morillo Internasional Indonesia.

\section{TINJAUAN PUSTAKA}

\section{A. Manajemen Sumber Daya Manusia}

Schuler dalạm Sutrisno (2016) mengatakan bahwa Manajemen Sumber DayaManusia (MSDM) yakni pengaakuan atas pentingnya seseorang tenaga kerja 
sumber daya yang penting yang berkontribusi terhadap perusahaan atas tujuan yang akan dicapai.

Menurut Arif Yusuf Hamali (2018:54) manajement SDM manusiaa adalah sbuah pndekatan yang strategis terhdap ketrampilan, motivasi, pengembangạn dan manajemen pengorganisasian sumber daya manusia. MSDM mengatur serta membentuk culture perusahaan secara proper, serta meng-input kegiatan-kegiatan yang mndukung nilai-nilai pokok dari perusahaaan tersebut demi memmastikan kberhasilannya.

Hasibuan (2017:94) dalam bahasannya mengatakan bahwa MSDM yakni sebuah ilmu atau seni untuk memenej hbungan karyawan serta perannya supaya effektif dan efficien mewujuddkan visi dan misi perusahaan tempatnyaa bekerja, serta pemenuhan hak hak dan kewajiban karyawan.

Merangkum beberapa deffinisi diatas, penulis menyimpulkan MSDM adalah suatu seni untuk mengatur orang lain dalam proses peranannya terhadap suatu tugas yang bertujuan memajukan perusahaan guna mencapai tujuan secara effeektif dan effisien.

\section{B. Fungsi Manajemen SDM}

mrumuskan fungsi-fungsi SDM sbagai berikut:

1) Planning

Planning atau Perencanaan (human resource planning) adalah merencanakan tenaga kerja secara efektifitas serta efisiensi agar sesuai dengan apa yang dibtuhkan perusahaan dalam membantu terwujudnya visi dan misi perusahaan.

2) Organizing

Organizing atau Pengorganisasian adalah proses mengatuur tugas dan kwenangan serta tanggungjawab tiaptiap individu dalam manajemen, sehingga mnjadi kesatuan untuk mncapai tujuan yang tlah dicanangkan sebelumnya.

3) Directing

Directing atau Pengarahan ialah kegiatan memberi arahan kepada setiap karyawan agar dapat bekerja dalam tim secara efektif dan efisiensii sehingga membantu perusahaan untuk mencapai tujuan yang dicanangkan.

4) Controlling

Controlling atau Pengendalian adalah kegiatan untuk bagaimana mengontrol setiap staff, agar senantiasa menjalankan peraturan yang tertuang dalam SOP atau Standar Operational Procedures serta mengerjakan sesuai dengan target. Jika ditemukan suatu 

minimum yang distandarisasi pemerintah

kesalahan, makan akan dilakukan tindakan yang diperlukan dalam hal meminimalisir setiap kesalahan yang ada untuk menyempurnakan perencanaan. Ini meliputi kedisiplikan karyawan, kerjasama dalam bekerja, pelaksanaan pekerjaan serta menjaga situasi dan kondisi lingkungan kerja.

5) Procurement

Procurement atau Pengadaan adalah proses pe narikan, seleksi, penem patan, orientasii, dan induksi agar mendapatkan kryawan yang berkompetensi.

6) Development

Development atau Pengembangan ialah meningkatkan skill secara teknis maupun teoritis, secara konsep dan moral seorang karyawan melalui proses pendidikan atau pelatihan yang diselenggarakan oleh perusahaan, melalui penyesuaian dengan kebutuhan perusahaan dimasa kini dan dimasa yang akan datang.

7) Compensation

Compensation atau Kompensasi yakni imbalan balas jasa yang diberikan kepada karyawan sebagai penghargaan atas pekerjaannya, secara adil dan layak, adil disni berarti imbalan sesuai dengan prestasi kerja nya, serta layak yakni dapat diartikan sebagai imbalan yang dapat memenuhi segala kebutuhan secara primer berdasarkan pada pemberian upah serta berdasarkan faktor internal maupun eksternal perusahaan.

8) Integration

Integration ataun Pengintegrasian adalah setiap kegiatan yang bertujuan untuk menselaraskan kepentingan karyawan dan perusahaan, sehingga mencapai krjasama yang saling menguntunggkan. Di satau sisi Perusahaan mndapatkan income sesuai target, disisi lain karyawan menerima insentif sesuai dengan hak-haknya. Hal ini menjadi sesuatu yang sulit dilakukan karena menyelaraskan kpentingan dua pihak yang bertolak-belakang.

9) Maintenance

Maintenance atau Pemeliharaan yakni kegiatan untuk pemeliharaan serta peningkatan setiap aspek mulai dari fisik, meental dan loyalitas karyawan, sehingga karyawan merasa loyal terhadap perusahaan hingga sampai masa pensiunnya. Maintenance yang baik adalah yang jika dilakukan melalui program ksejahteraan karyawan berdasar atas kebutuhan karyawan dan dalam berpedoman pada konsistensi internal dan eksternal perusahaan.

10) Discipline

Discipline atau Kedisiplinan yang adalah fungsi Manajemen Sumber Daya Manusia yang paling penting sekaligus merupakan kunci tercapai suatu tujuan. 
adalah keinginan dan kesadaran untuk berlaku sesuai dengan standar operasional serta norma berlaku.

\section{1) Separation}

Separation atau Pemberhentian yakni proses PHK (Pemutusan Hubungan Kerja) karyawan dari perusahaan tempatnya berkerja. Pemutusan hubungan kerja ini dapat disebabkan oleh berbagai faktor, diantaranya keinginan karyawan itu sendiri, keinginan perusahaan, sebab kontrak kerja yang telah habis atau berakhir dan tidak diperpanjang, memasuki masa pensiun, dan hal-hal lainnya. Pemberhentian ini telah diatur dalam UU No. 12 tahun 1964.

\section{Lingkungan Kerja}

Lingkungan Kerja adalah setiap instrumentasi dan material yang dihadapi dimana seseorang bekerja, metode kerjanya, serta pengaturan kerjanya baik sebagai perseorangan maupun sebagai kelompok.

Menurut Danang Sunyoto (2015:43) Lingkungan kerja adalah segala sesuatu yang ada di sekitar para pekerja dan yang dapat mempengaruhi pribadinya dalam bertugas, misalnya musik, penerangan, dan lain-lain.

Lingkungan kerja menurut Afandi (2018:66) yakni setiap hal yang ada dalam lingkungan karyawan bekerja sehingga mempengaruhi dirinya saat menjalankan kelembaban, pentilasi, penerangan, kegaduhan, kebersihan tempat kerja, dan ATK yang mmemadai.

Lingkungan kerja dapat diartikan sebagai keseluruhan alat perkakas yang dihadapi, Lingkungan sekitarnya dimana seorang pekerja, metode kerjanya, sebagai pengaruh kerjanya baik sebagai perorangan maupun sebagai kelompok.

Berdasarkan bberapa pengertian Lingkungan kerja diatas maka dapat disimpulkan bahwa Lingkungan kerja merupakan segala hal yang terdapat di lingkup karyawan yáng dapat mempengaruhi karyawan terssebut dalam melaksanakan kewajibannya agar karyawan nyaman dan betah di tempat kerjanya.

\section{Parameter Lingkungan Kerja}

Pengukuran Lingkungan kerja menurut Sedarmayati $\quad(2014 ; 46) \quad$ yakni

Penerangan, mengukur cukup atau tidaknya penerangan, (2) Suhu Udara, terkait temperature dalam ruang kerja, (3) Kebisingan, (4) Penggunaan warna, (5) Ruang gerak yang diperlukan, (6) Keamanan, serta (7) Hubungan karyawan.

\section{E. Indikator Pengalaman Kerja}

Menurut Fooster (2014) ada hal-hal yang dapat mengukur pengalaman kerja seorang karyawan, diantaranya adlah:

1) Masa Kerja, masing-masing karyawan memiliki jam terbang nya masingmasing, seberapa lama ia berada pada pekerjaannya dapat menjadi pnentu 


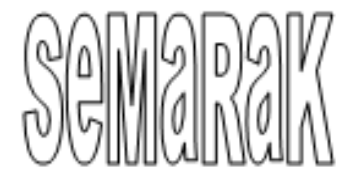

Jurnal Semarak,Vol.4,No.1,Februari 2021, Hal (23-40)

@ Prodi Manajemen Fakultas Ekonomi Universitas Pamulang berpe

ngalaman atau tidaknya seorang karyawan.

2) Pengetahuan atas Bidang Pekerjaan, dan

3) Tingkat Peenguasaan karyawan atas pkerjaan dan pralatan

\section{F. Kinerja Karyawan}

Kotler dan Armstrong (2013) menyatakan bhwa di tahap evaaluasi, pelanggan akan meenentukan per- ingkat

Kinerja karyawan merupakan suatu hasil yang dicapai oleh pekerja dalam pekerjaannya menurut kriteria tertentu yang berlaku untuk suatu pekerjaan.

Anwar Prabu Mankunegara (2016) mengatakan Kinerja hasil pencapaian krja baik kualitas maupun kuantitas seorang karyawan dalam menjalankan tugas dan tnggung jawabnya.

Hasibuan (2016:160) Menjelaskan Kinerja ialah pencapaian hasil kerja karyawan dalam job-desk nya, usahausaha yang dilakukan, kcakapan dalam berbagai kesempatan.

\section{G. Unsur-unsur Kinerja Karyawan}

Menurut Hasibuan (2016:59) mnjelaskan unsur kiinerja dlaam beberapa point diantaranya:

(1) Prestasi, yakni Penilaian kinerja yang baik yang dihasilkan setiap karyawan, (2) Kedisiplinan mengkur Kepatuhan akan peraturan dan tata tertib dalam bekerja,

(3) Kreativitas, Ukuran karyawan utk dapat menciptakan sesuatu yang baru untuk dapat menyelesaikan pekerjaan nya lebih baik. (4) Bekerja Sama, kesediaan dan partisipasi karyawan utk bekerjasama dengan sesamanya secara vertical maupun horizontal, antar tim atau sesame anggota tim untuk mencapai kinerja yang maksimal, (5) Kecakapan, dan (6) tanggung jawab.

\section{H. Indikator Kinerja Karyawan}

Robbins (2016) menyatakan bahwa hal-hal yang dapat mengukur Kinerja karyawan adalah sebagai berikut:

1) Kualitas

Terukur berdasarkan keterampilan dan skill yang dimiliki keryawan atas penyelesaian tugas yang dibeirkan

2) Kuantitas

Terukur berdadsarkan jumlah pekerjaan baik unit pkerjaan, jumlah aktifitas dan banyak tugas yang diselesaikan

3) Ketepatan waktu

Ukuran ketepatan waktu karyawan dari kehadiran, penyelesaian tugas dan tanggung jawab dan output atau keluaran yang dihasilkan

4) Efektivitas

Seberapa efektif terkait penggunaan sumber daya perusahaan dan waktu yang dibutuhkan

5) Kemandirian

Tanggung jawab sorang karyawan terhadap tugas yang diberikan dan menjaga komitmen sesuai dengan fungsinya dalam perusahaan

\section{Hipotesis Penelitian}

Berikut dibawah ini dugaan sementara yang dapat dihasilkan dari penelitian berdasarkan paparan 
Dengan menggunakan Metode

di latarbelakang, mindmap maupun

kajianteori:

$\mathrm{H}_{01}$ : Diduga tidak adanya pengaruh LingkunganKerja terhadap

KinerjaKaryawan PT. Morillo Internasional Indonesia secara parsial

$\mathrm{Ha}_{1}$ : Diduga adanya pengaruh LingkunganKerja terhadap KinerjaKaryawan PT. Morillo Internasional Indonesia secara parsial $\mathrm{H}_{02}$ : Diduga tidak adanya pengaruh Pengalaman kerja terhadap KinerjaKaryawan PT. Morillo Internasional Indonesia scra parisal

$\mathrm{H}_{\mathrm{a} 2}$ : Diduga adanya pengaruh Pengalaman kerja terhadap KinerjaKaryawan PT. Morillo Internasional Indonesia scra parsial

$\mathrm{H}_{\mathrm{O} 3}$ : Diduga tidak terdapat pengaruh signifikan Lingkungan kerja dan Pengalaman kerja secara bersama-sama terhadap Kinerja karyawan di PT. Morillo Internasional Indonesia secara simultan $\mathrm{H}_{\mathrm{a} 3}$ : Diduga terdapat pengaruh signifikan Lingkungan kerja dan Pengalaman kerja secara bersama-sama terhadap Kinerja karyawan di PT. Morillo Internasional Indonesia secara simultan

\section{METODE PENELITIAN}

Tempat dilakukannya penelitain adalah di PT. Morillo Internasional Indonesia beralamat di JL. Lebak Bulus 1 No 2 Cilandak, DKI Jakarta. 12440 Indonesia penelitian kuantitatif, peneliti menguji sampel dari populasi, menganalisa data statistic utk menguji dugaan sementara.

Menurut Kuncoro (2009), Riset dekriptif digunakan untuk membuat gambaran terhadap karakteristik responnden, melihat pada bentuk penelitian ini, tipe kausal adalah penelitian yang mengukuur kekuatan hbungan 2 (dua) atau lbih variable serta relasi diantara var bebas dan var terikat nya. Berguna untuk menganalisis hubungan - hubungan yang saling mempengaruhi.

Dalam penelitian ini seluruh subjek atau objek di teliti sehingga dapat disebut sebagai sampell jenuh.

Yang menurut Sugiono (2012) Sample Jenuh adalah teknik yang mnjadikan seluruh anggota populasi mnjadi anggota saample. Dalam penelitian ini seluruh karyawan PT Morillo Internasional Indonesia sebanyak 55 (lima puluh lima) orang dijadikan sebagai sampel penelitian.

Dalam penelitian ini, instrumen yang digunakan adalah kuesioner.

Penelitian skor dan poin dilaksanakan dalam bentuk skala Likert.

\section{Tabel 4}


Jurnal Semarak,Vol.4,No.1,Februari 2021, Hal (23-40)

@ Prodi Manajemen Fakultas Ekonomi Universitas Pamulang

؛ Gambar 1. Logo PT. Morillo Internasional

\begin{tabular}{|c}
\hline Alternat \\
\hline Sangi \\
\hline Setojuene \\
\hline Ragu-1 1. Va \\
\hline Tidak Setuju \\
\hline Sangat Tidak Se \\
\hline
\end{tabular}

Indonesia

IV. HASIL DAN PEMBAHASAN

\section{A. Gambaran Objek Penelitian}

PT. Morillo Internasional Indonesia berlamatkan di Jl. Jl. Lebak Bulus I No.2, Lb. Bulus, Cilandak, Kota Jakarta Selatan, Daerah Khusus Ibukota Jakarta 12440, Indonesia.

Peursahaan yang bergerak di bidang penyedia waterproof dan membran bakar untuk memenuhi kebutuhan daya tahan bangunan dari cuaca dan iklim Indonesia yang memiliki tingkat curah hujan yang tinggi, memproteksi gedung dan bangunan dari kebocoran melalui solusi ternbaik dengan teknologi waterproofing system bergaransi dan after sales yang terbaik serta teknisi professional dan tenaga ahli berdedikasi tinggi.

Berikut adalah Logo Perusahaan dari PT Morillo Internasional Indonesia

$$
\text { (C) Morillo }
$$

melihat seberapa besar akurasi alathitung berupa kuisioner sebagai instrumentasi penelitian dapat menghitung secara valid sesuai dengan keadaan sebenarnya. Berdsasrkan pada nilai r-tabel dengan kondisi jumlah populasi sekaligus sample penelitian sebanyak 55 orang maka nilai df $=55$, dengan singinfikansi 5\%, mala nulai r-tabel sama dengan 0,260. Perbandingan rhituing dengan r-tabel jika lebih besar dari r-tabel, maka nilainya valid, sementara jika r-hitung lebih kecil drpd r-tabel maka tidak valid, dan pernyataan tersebut harus diubah atau diganti dengan pernyataan lain.

Fungsi darinya adalah untuk menguji butir-butir kuesioner atau instrumen yang diukur untuk mengetahui ketepatan datanya dan sjauh mana vailditas dapat mengukur.

Formula ProductMoment:

$r_{x y}=\frac{N \Sigma x y_{-(\Sigma x)}\left(\sum y\right)}{\sqrt{\left(N \Sigma x^{2}-\left(\sum x\right)^{2}\left(N \Sigma y^{2}-(\Sigma y)^{2}\right)\right.}}$

Note: 
Jurnal Semarak,Vol.4,No.1,Februari 2021, Hal (23-40)

@Prodi Manajemen Fakultas Ekonomi Universitas Pamulang $r_{x y}=$ Koefisien korelasi antara variabel table hasil validitas sebelumnya $\Sigma x y=$ Jumlah perkalian antara variabe menunjukkan bahwasanya seluruh $\sum \chi^{2}=$ Jumlah dari kuadrat nilai $\mathrm{x}$ scoring $\mathrm{r}_{\text {hitung }}$ lebih besar dari nilai $\sum y^{2}=$ Jumlah darikuadrat $\mathrm{r}_{\text {Table }}(0,1832)$. Karenanya, dapat diambil ksimpulan bhwa prnyataan $(\Sigma x)^{2}=$ Jumlah nilai $X$ kemudian di dalam survey ini validd dan dapat $\left(\sum y\right)^{2}=$ Jumlah nilai Y kemudian dil digunakan sbagaai instrumentasi penelitian.

Tabel 5 Hasil Uji Validitas

\begin{tabular}{|c|c|c|c|c|}
\hline \multicolumn{5}{|c|}{ Hasil Uji Validitas Lingk.Kerja } \\
\hline No & Poin Quiz & $\begin{array}{c}\text { Nilai } \\
\text { tabel }\end{array}$ & $\begin{array}{c}\text { Nilai r } \\
\text { hitung }\end{array}$ & $\begin{array}{c}\text { Result } \\
\text { VALID? }\end{array}$ \\
\hline 1 & LK1 & 0,260 & 0,639 & YES \\
\hline 2 & LK2 & 0,260 & 0,307 & YES \\
\hline 3 & LK3 & 0,260 & 0,665 & YES \\
\hline 4 & LK4 & 0,260 & 0,515 & YES \\
\hline 5 & LK5 & 0,260 & 0,673 & YES \\
\hline 6 & LK6 & 0,260 & 0,462 & YES \\
\hline 7 & LK7 & 0,260 & 0,470 & YES \\
\hline 8 & LK8 & 0,260 & 0,468 & YES \\
\hline \multicolumn{5}{|c|}{ Pengalaman Kerja } \\
\hline 1 & PK1 & 0,260 & 0,491 & YES \\
\hline 2 & PK2 & 0,260 & 0,504 & YES \\
\hline 3 & PK3 & 0,260 & 0,608 & YES \\
\hline 4 & PK4 & 0,260 & 0,545 & YES \\
\hline 5 & PK5 & 0,260 & 0,337 & YES \\
\hline 6 & PK6 & 0,260 & 0,686 & YES \\
\hline 7 & PK7 & 0,260 & 0,741 & YES \\
\hline 8 & PK8 & 0,260 & 0,689 & YES \\
\hline \multicolumn{5}{|c|}{ Buying Decision } \\
\hline 1 & KN1 & 0,260 & 0,640 & YES \\
\hline 2 & KN2 & 0,260 & 0,639 & YES \\
\hline 3 & KN3 & 0,260 & 0,705 & YES \\
\hline 4 & KN4 & 0,260 & 0,634 & YES \\
\hline 5 & KN5 & 0,260 & 0,600 & YES \\
\hline 6 & KN6 & 0,260 & 0,571 & YES \\
\hline 7 & KN7 & 0,260 & 0,643 & YES \\
\hline 8 & KN8 & 0,260 & 0,561 & YES \\
\hline \multicolumn{5}{|c|}{} \\
\hline
\end{tabular}

Selaras dengan pernyataan Sugiyono (2013) dalam bukunya yang mengatakan bahwa Hasil perhitungan uji validitas sebagaimana

\section{Pengujian Relia bilitas}

Fungsi dari pengujian ini adalah untuk menguji konsistensi indeks data yang menunjukkan sejauh mana suatu alat ukur dapat dipercaya atau dapat diandalkan.

\section{Table 6 Hasil Reliabilitas}

\begin{tabular}{|c|c|c|c|}
\hline Variabel & $\begin{array}{c}\text { Cronbach's } \\
\text { Alpha }\end{array}$ & $\begin{array}{c}\text { N of } \\
\text { items }\end{array}$ & Keterangan \\
\hline Lingkungan Kerja & 0,616 & 8 & Reliabel \\
\hline Pengalaman Kerja & 0,703 & 8 & Reliabel \\
\hline Kinerja & 0,776 & 8 & Reliabel \\
\hline \multicolumn{2}{|l}{ Sumber: Hasil Pengolahan SPSS 23 }
\end{tabular}

Dari hasil Reliability test diperoleh nilai Cronbach alpha semua variabel > 0,600. Hal ini sesuai dengan Sugiyono (2013) dalam bahasannya, dimana semua nilai Cronbach Alpha yang terhitung > 0,60 dan aartinya semua data bersifat reliable, Karenanya, dapat di simpulkan bhwa setiap pernyataan dalam quiz ajeg atau reliable serta consistent, srta dapat di gunakan sebaagai instrumentasi penelitian.

\section{Test Classic'sAssuption}

a. Normality Test

$$
\text { Penguujian normalitas }
$$

dilakukan dengan mlakukan uji 
Jurnal Semarak,Vol.4,No.1,Februari 2021, Hal (23-40)

@Prodi Manajemen Fakultas Ekonomi Universitas Pamulang

terhadap nilai

sisa atau residue score, sedang, testing

dilakukan dengan menggunakan graffik

p-plot dan kolmogrov smiirnov test..

Basis pengammbilan keputusan dlam

Normality test yaitu:

1. Jika Asymp.sig score lebih besar $5 \%$, maka data berdistribusi normal

2. Jika Asymp.sig score lebih besar $5 \%$, maka data tidak berdistribusi normal.

Pada pengujian normalitas ini dapat dilihat dari Table di bawah ini:

Table 7 Hasil Uji Normalitas

One-Sample Kolmogorov-Smirnov Test

\begin{tabular}{|c|c|c|}
\hline & & \begin{tabular}{|c}
$\begin{array}{c}\text { Unstandardized } \\
\text { Residual }\end{array}$ \\
\end{tabular} \\
\hline $\begin{array}{l}\mathrm{N} \\
\text { Normal Parameters } \\
\text { Most Extreme Differences } \\
\text { Kolmogorov-Smirnov Z } \\
\text { Asymp. Sig. (2-tailed) }\end{array}$ & $\begin{array}{l}\text { Mean } \\
\text { Std. Deviation } \\
\text { Absolute } \\
\text { Positive } \\
\text { Negative }\end{array}$ & $\begin{array}{r}55 \\
.0000000 \\
3.05239374 \\
.111 \\
.111 \\
-.098 \\
.820 \\
.512\end{array}$ \\
\hline \multicolumn{3}{|l|}{$\begin{array}{l}\text { a. Test distribution is Normal. } \\
\text { b. Calculated from data. }\end{array}$} \\
\hline
\end{tabular}

didapatkan nilai Unstandardized

Residual Regresi sebesar 0,512 atau

0,05. Sehingga dapat dikemukakan bahwa seluruh data dalam penelitian ini telah memenuhi asumsi data berdistribusi normal.

\section{b. Multikolinieritas Test}

Pengujian Multiko- linieritas mendasari pengambilan kputusannya dengan beberapa point berikut:

\section{Tolerance Score}

a. Multiklonieritas tiidak akan ada, apabila tolerance score kurang dari 0,10.

b. Multiklonieritas ada apabila tolerance score $\leq 0,10$.

2. Berdasarkan pada variasi faktor inflasi atau VIF

a. Multiklonieritas tidak akan ada, jika tolerance score < 10,00 .

b. Multiklonieritas ada jika tolerance score $\geq 0,10$.

Pengujian multi kolinieritas mengunakan analisis yang dibantu program aplikasi SPSS versi 23.0, dengan ringkasan hasil uji multi sebagai berikut.

Table 8 Hasil Uji Multi kolinier

\begin{tabular}{|c|c|c|c|c|c|c|}
\hline \multirow{2}{*}{\multicolumn{2}{|c|}{ Model }} & \multicolumn{2}{|c|}{$\begin{array}{l}\text { Unstandardized } \\
\text { Coefficients }\end{array}$} & \multirow{2}{*}{\begin{tabular}{|c|}
$\begin{array}{c}\text { Standardized } \\
\text { Coefficients }\end{array}$ \\
Beta \\
\end{tabular}} & \multicolumn{2}{|c|}{$\begin{array}{l}\text { Collinearity } \\
\text { Statistics }\end{array}$} \\
\hline & & B & $\begin{array}{l}\text { Std. } \\
\text { Error }\end{array}$ & & Tolerance & VIF \\
\hline \multirow{3}{*}{1} & (Constant) & 1.438 & 4.742 & & & \\
\hline & Lingkungan_Kerja & .486 & .142 & .395 & .806 & 1.240 \\
\hline & Pengalaman_Kerja & .449 & .135 & .385 & .806 & 1.240 \\
\hline
\end{tabular}

Melihat ringkasan hasil uji multi kolinie ritas diatas, nilai tolerance yang berada dibawah 0,1 serta nilai variasi faktor inflasi yang kurang dari 10, dapat peneliti simpulkan bahwa tidak terdapat gejala-gejala multi kolinieritas.

c. Test Heterokedastisitas

Test Heterokedastisitas adalaah uji yang menilai apakah ada ketidaksamaan varian dari residual 


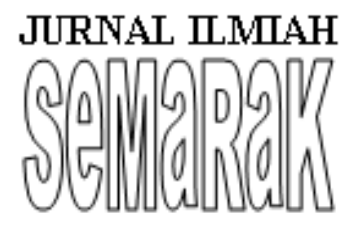

pengamatan pada model regresi linear. Pendeteksiannya dilakukan dengan melihat ada tidaknya pola tertentu dalam grafik dimana sumbu $\mathrm{X}$ dan $\mathrm{Y}$ telah diproduksi.

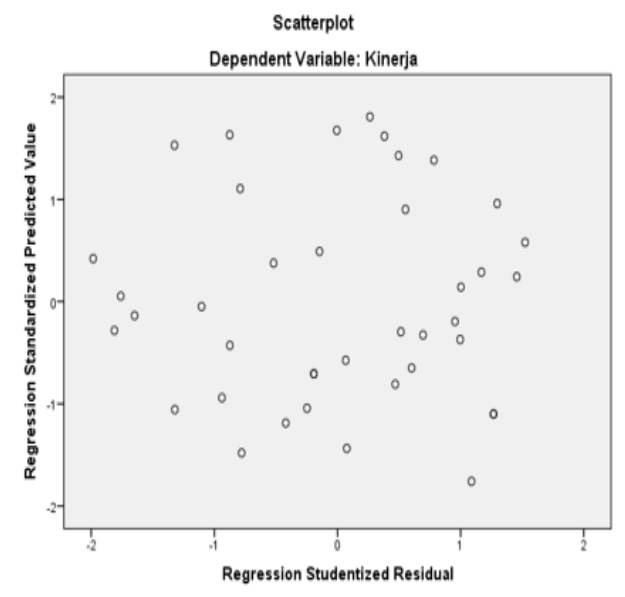

Sumber: Hasil Pengolahan SPSS 23

\section{Gambar 2. Uji Heterokedastisitas}

Berdasarkan gambar diagram pada Gambar 2 dapat dilihat bahwa data (titik-titik) secara random menyebar serta tidak membentuk pola tertentu. Hal ini menunjukkan bahwa regresi tidak mengalami gangguan heteroskedastisitas.

\section{Pengaruh Secara Partial}

Uji parsial atau individual digunakan untk mngetahui apkah satu atau lebih independence variable dan pengaruhnya terhadap dependence variabel. Pertimbangannya melihat berdasarkan nilai probabilitas dan nilai signifikansinya, dengan kondisi (1) Jika nilai signifikansi lebih besar
Table 9 Hasil Uji Partial t

\begin{tabular}{|c|c|c|c|c|c|c|}
\hline \multirow{2}{*}{\multicolumn{2}{|c|}{ Model }} & \multicolumn{2}{|c|}{$\begin{array}{c}\text { Unstandardized } \\
\text { Coefficients }\end{array}$} & \multirow{2}{*}{$\begin{array}{c}\begin{array}{c}\text { Standardized } \\
\text { Coefficients }\end{array} \\
\text { Beta }\end{array}$} & \multirow[t]{2}{*}{$t$} & \multirow[t]{2}{*}{ Sig. } \\
\hline & & $\bar{B}$ & Std. Error & & & \\
\hline \multirow{3}{*}{1} & (Constant) & 1.438 & $\overline{4.742}$ & & .303 & .763 \\
\hline & Lingkungan_Kerja & 486 & .142 & .395 & 3.414 & .001 \\
\hline & Pengalaman_Kerja & 449 & .135 & .385 & 3.326 & .002 \\
\hline
\end{tabular}

Sumber: Hasil Pengolahan SPSS 23

Hasil Pengujian Pengaruh Lingkungan TerhadapKinerja Karyawan

Berdasarkan Tabel 9 dapat dilihat nilai t-hitung pada variabel Lingkungan_kerja $\left(\mathrm{X}_{1}\right)$ lebihbesar dari nilai t-tabel $(3,414>1,960)$ dengan nilai signifikansi dari variabel Lingkungan_Kerja $\left(\mathrm{X}_{1}\right) \quad 0,001<0,05$ sehingga Ho ditolak dan Ha diterima, yang berarti terdapat pengaruh yang positif dan signifikan Lingkungan_kerja $\left(\mathrm{X}_{1}\right) \quad$ thdp Kinerja_Karyawan(Y).

\section{Hasil Pengujian Pengaruh PengalamanKerja Terhadap \\ KinerjaKaryawan}

Berdasarkan Tabel 9 dapat dilihat nilai t-hitung pada variabel Lingkungan_kerja $\left(\mathrm{X}_{1}\right)$ lebih besar dari nilai t-tabel $(3,326>1,960)$ dengan nilai signifikansi dari variabel Pengalaman_Kerja $\left(\mathrm{X}_{2}\right) \quad 0,002<0,05$, 
Jurnal Semarak,Vol.4,No.1,Februari 2021, Hal (23-40)

@Prodi Manajemen Fakultas Ekonomi Universitas Pamulang sehingga Ho

Model Summary b

ditolak dan Ha diterima, yang berarti terdapat pengaruh yang positif dan signifikan Pengalaman_kerja $\left(\mathrm{X}_{2}\right)$ terhadap Kinerja_Karyawan.

\section{Pengaruh Secara Bersamaan (Simultanous)}

Uji pengaruh secara bersama atau simultan, dengan kata lain Uji F mnejelaskan ada atau tidaknya signifikansi hasil analisis regresi. Disini digunakan signifikansi $5 \%$ atau 0,05; dimana jika nilai sig. lebih besar daripada 0,05 maka $\mathrm{H}$ nol ditolak dan $\mathrm{H}$-a diterima

Table 10 Hasil Uji Simultan F ANOVA $^{\mathrm{a}}$

\begin{tabular}{|l|r|r|r|c|c|}
\hline Model & Sum of Squares & df & Mean Square & F & Sig. \\
\hline Regression & 392.622 & 2 & 196.311 & 20.290 & $.000^{\mathrm{b}}$ \\
1 Residual & 503.124 & 52 & 9.675 & & \\
Total & 895.745 & 54 & & & \\
\hline
\end{tabular}
a. Dependent Variable: Kinerja
b. Predictors: (Constant), Pengalaman_Kerja, Lingkungan_Kerja

Berdasarkan Tabel 10 dapat dilihat nilai signifikasi adalah $0,000<0,05$ maka Ho ditolak dan $\mathrm{Ha}$ diterima, maka dapat dinyatakan bahwa lingkungan kerja dan pengalaman kerja secara bersama-sama berpengaruh terhadap kinerja Karyawan.

\section{Koefiisien Determiinasi}

KoefisiensiDeterminasi dipakai untuk mnentukan besar pengaruh antar variable bebas ke variable terikat.

Table 11 Koef Determ inasi

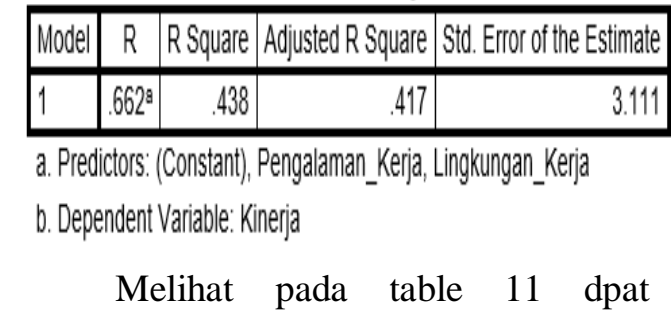
diktahui hasil (R-Square) sebesar 0,438 yang artinya 43,8\% kinerja Karyawan dapat djelaskan oleh var.lingkunganKerja dan pengalamanKerja. Sedangkan sisanya $56,2 \%$ tidak dijelaskan dijelaskan model penelitian ini.

\section{KESIMPULAN\& SARAN}

\section{A. Kesimpulan}

Berikut Point-point yang dapat peneliti simpulkan berdasar pada analisis ayng dilakukan sebeluumnya:

1. LingkunganKerja (LK) berpengaruh signifikan terhadap kinerja Karyawan PT. Morillo Internasional Indonesia. Hal ini dapat dilihat thitung $(3,414)>\mathrm{t}$-tabel $(1,960)$, sig. value 0,001 , mka $\mathrm{H} 0$ ditolah $\mathrm{Ha}$ diterima. Artinya berpengaruh dan signifikan

2. Pengalaman kerja berpengaruh signifikan terhadap kinerja Karyawan PT. Morillo Internasional Indonesia. Hal ini dilihat berdasar t$\operatorname{hitung}(3,326)>\mathrm{t}$-tabel $(1,960)$, sig. value 0,002 , mka $\mathrm{H} 0$ ditolah $\mathrm{Ha}$ diterima. Artinya berpengaruh dan signifikan. 
Jurnal Semarak,Vol.4,No.1,Februari 2021, Hal (23-40)

@ Prodi Manajemen Fakultas Ekonomi Universitas Pamulang

3. Lngk sehingga mempermudah Karyawan dalam

ungan kerja dan pengalaman kerja berkerja, sehingga kinerja Karyawan dan secara bersama sama berpengaruh perusahaan semakin meningkat.

signifikan terhadap kinerja

Karyawan PT. Morillo Internasional

Indonesia. Hal ini dapat dilihat dari nilai signifikasi uji $\mathrm{F}$ yaitu 0,000 atau lebih kecil dari 0,05 maka Ho ditolak dan Ha diterima, maka dapat dinyatakan bahwa lingkungan kerja dan pengalaman scara simultan berpengaruh terhadap kinerja Karyawan.

4. Hasil perhitungan KoefisienDeterminasi atau R-Square $\mathrm{dr}$ variable Lingkungan $\left(\mathrm{X}_{1}\right)$ dan Pengalaman $\left(\mathrm{X}_{2}\right)$ terhadap Kinerja (Y) adalah sebesar 43,8\% sedangkan sisanya sebesar 56,2\% dipengaruhi oleh variabel lain yang tidak di teliti.

\section{B. Saran}

Untuk PT Morillo Internasional Indonesia, sebagai objek penelitian, Untuk lingkungan kerja, pihak perusahaan untuk lebih memperhatikan tata letak ruang kerja yang nyaman dan memberi penerangan yang cukup di ruang kerja karyawan.

Untuk pengalaman kerja, pihak perusahaan untuk lebih memperhatikan Karyawan yang belum memiliki kompetensi di bidangnya dan belum memiliki pengalaman kerja yang cukup lama, agar diberikan soft skills training untuk meningkatkan kompetensi mereka,

\section{Bagi Peneliti selanjutnya}

Sehubungan penelitian ini memiliki keterbatasan dalam melakukan penelitian, disarankan bagi peneliti selanjutnya yang ingin meneliti terkait variabel yang terdapat dalam penelitian ini, yaitu lingkungan kerja, pengalaman kerja dan kinerja Karyawan, agar penelitian selanjutnya dapat mengembangkan variabel-variabel lain sehingga dapat sebagai referensi untuk meneliti variabel yang belum pernah dilakukan maupun menggunakan objek penelitian lainnya dan dengan penambahan jumlah responden di objek penelitian yang berbeda.

Faktor kesalahan yang mungkin terjadi adalah pernyataan pada kuesioner yang ambigu. Faktor lainnya tidaklah menentang teori para ahli yaitu mengenai fenomena yang terjadi pada Karyawan. Lingkungan kerja sudah tidak lagi menjadi faktor dominan bagi kinerja Karyawan PT. Morillo Internasional Indonesia. Hal ini dilakukan untuk mengetahui apakah penyataan yang dibuat sudah sesuai dengan yang variabel yang akan diukur. Memperbanyak jumlah responden juga dapat dilakukan sehingga pengkajian lebih akurat terhadapkinerjaKaryawan.

\section{DAFTAR PUSTAKA}


(2018). Manajemen Sumber Daya Manusia. Cetakan Pertama. Riau: ZANAFA PUBLISHING.

Athoillah, Anton. (2016). Dasar-dasar Manajemen. Bandung: CV Pustaka Setia.

Danang, Sunyoto. (2016). Manajemen Sumber Daya Manusia. Jakarta: PT Buku Seru.

Edy, Sutrisno. (2016). Manajemen Sumber Daya Manusia. Cetakan ke-8. Jakarta: Prenada Media Group.

Edison, Emron. Yohny anwar, Imas komariyah. (2016). Manajemen Sumber Daya Manusia. Bandung: Alfabeta.

Fahmi, Irham. (2016). Pengantar Manajemen Sumber Daya Manusia: Konsep dan Kinerja. Jakarta: Mitra Wacana Media.

Ferdinand, Augusty. (2016). Metode Penelitian Manajemen. BP Universitas Diponegoro. Semarang.

Firmansyah, Hendry (2014). Pengaruh Lingkungan Kerja dan Pengalaman Kerja terhadap Kinerja Karyawan. PT. Adi Mix Jakarta. Jurnal Ekonomi UIN Syarif Hidayatullah Jakarta.

Foster. Bill. (2014). Pembinaan Untuk Peningkatan Kinerja Karyawan. PPM: Jakarta.

Ghozali, Imam. (2016). Structural Equation Modeling, Metode Alternatif dengan Partial Least Square (PLS). Edisi 4 Semarang: Badan Penerbit Universitas Diponegoro. Aplikasi Menggunakan Smart PLS 3.0 Untuk Penelitian Empiris. BP Undip. Semarang.

Ghozali, Imam. (2016). Aplikasi Analisis Multivariete Dengan Program IBM SPSS 23 (Edisi 8). Cetakan ke VIII. Semarang: Badan Penerbit Universitas Diponegoro.

Foster, Bill. (2015). Pembinaan untuk Peningkatan Kinerja Karyawan. PPM. Jakarta. Penerjemah: Ramlan

Hamali, Arif Yusuf. (2016). Pemahaman manajemen sumber daya manusia. Yogyakarta: CAPS.

Hasibuan, M. S. (2016). Manajemen Sumber Daya Manusia. Jakarta: PT Bumi Aksara.

Krisnaldy, K., Pasaribu, V. L. D., \& Batubara, A. S. (2020). Analisis Pengaruh Kedisiplinan Terhadap Performa Pegawai Kelurahan Rempoa, Kota Tangerang Selatan. Jurnal Mandiri: Ilmu Pengetahuan, Seni, Dan Teknologi, 4(2), 131-138.

Krisnaldy, K., Pasaribu, V. L. D., \& Senen, S. (2019). Pengaruh Budaya Organisasi, Lingkungan Kerja Dan Iklim Organisasi Terhadap Motivasi Pegawai Serta Dampaknya Terhadap Kepuasan Kerja. Jurnal Semarak, 2(2), 164-183.

Mangkunegara Anwar Prabu A.A. (2015). Manajemen Sumber Daya Manusia. Bandung: PT. Remaja Rosdakarya

Mangkunegara, A. P. (2017). Manajemen Sumber Daya Manusia Perusahaan. Bandung: PT REMAJA ROSDAKARYA.

Manullang, M. (2016), Dasar-dasar Manajemen, Yogykarta: Gadjah Mada University Press. 


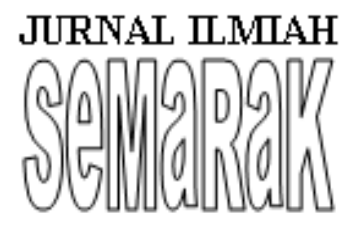

Fauzia (2017). Pengaruh Pengalaman

Kerja Dan Lingkungan Kerja Terhadap Produktivitas Kerja

Karyawan Di Pt. White Oil Nusantara Manyar Gresik. Jurnal Ekonomi Volume 06, Nomor 01, Juli 2017 Hal $51-56$.

Nurlaely M, Asri Laksmi, Riani. (2016). Pengaruh Disiplin Kerja, Motivasi Kerja, Kepuasan Kerja dan Kompetensi Terhadap Komitmen Organisasi. Jurnal Ekonomi Manajemen Sumber Daya, Vol 18, No.,10-19.

Pasaribu, V. L. D., Susanti, F., \& Hartuti, E. T. K. (2019). Memotivasi Siswa dan Siswi SMK Letris Indonesia di Dalam Menentukan Pilihan Untuk Melanjutkan Pendidikan Atau Bekerja Setelah Lulus Sekolah. Jurnal Pengabdian Dharma Laksana, 1(2), 161-172.

Pasaribu, V. L. D., \& Krisnaldy, K. (2018). ANALISIS KEPUASAN JAMA'AH PADA KINERJA DEWAN KEMAKMURAN MASJID AL-HIDAYAH PERIODE TAHUN 2017. KREATIF: Jurnal Ilmiah Prodi Manajemen Universitas Pamulang, 6(4), 41-51.

Pasaribu, V. L. D., Krisnaldy, K., \& Warasto, H. N. (2020). Pengaruh Gaya Kepemimpinan, Disiplin Kerja Dan Kompensasi Terhadap Kinerja Pegawai (Studi kasus kelurahan Pisangan Ciputat). Jurnal Disrupsi Bisnis: Jurnal Ilmiah Prodi Manajemen, Fakultas Ekonomi, Universitas Pamulang, 3(1).

Pasaribu, V. L. D., \& Krisnaldy, K. (2020). PENGARUH GAYA KEPEMIMPINAN, DISIPLIN KERJA DAN KOMPENSASI TERHADAP HASIL KINERJA KARYAWAN KELURAHAN CIPUTAT. PROCEEDINGS UNIVERSITAS PAMULANG, 1(1).

Priatna, Cepi. (2015). Perilaku Organisasi. PT. Remaja Rosdakarya, Bandung. Organizational Behavior. Edition 15. New Jersey: Pearson Education

Siagian, Sondang P. (2014). Manajemen Sumber Daya Manusia. Jakarta: PT Bumi Aksara

Simanjuntak. Widodo (2015). Manajemen Pengembangan Sumber Daya Manusia. Pustaka Pelajar: Yogyakarta

Sinambela, D. P. (2016). Manajemen Sumber Daya Manusia. Jakarta: PT Bumi Aksara.

Sedarmayanti. (2015). Manajemen Sumber Daya Manusia. Bandung: PT. Refika Aditama.

Sedarmayanti. (2016). Manajemen Sumber Daya Manusia, Reformasi Birokrasi dan Manajemen Karyawan Negeri Sipil (cetakan kelima). Bandung : PT Refika Aditama.

Sinambela, Lijan Poltak. (2017). Manajemen Sumber Daya Manusia, Cetakan ke2. Jakarta: Bumi Aksara.

Sugiyono, Prof Dr;. (2016). Metode Penelitian Pendekatan Kuantitatif, Kualitatif, dan $R \& D$. Bandung: Alfabeta.

Sugiyono. (2016). Metode Penelitian Kuantitatif, Kualitatif dan $R \& D$, Cetakan ke-24. Bandung: Alfabeta.

Sujarweni, V. Wiratna. (2016). Metode Penelitian: Lengkap, Praktis, dan Mudah Dipahami. Yogyakarta: Pustaka Baru Press.

Trijoko Setyo Riyanto. (2016). Pengaruh Pendidikan dan Pengalaman Kerja 


\section{Terhadap}

Kinerja Karyawan Pada PT. Global

Informasi Bermutu. Jurnal MIX,

Volume III, No. 1

Widodo, S. E. (2016). Manajemen

Pengembangan Sumber Daya

Manusia. Yogyakarta: Pustaka Pelajar.

Widodo, Sri. (2016). Manajemen Sumber Daya Manusia: Teori,

Perencanaan Strategi, Isu-isu

Utama dan Globalisasi, Manggu Media, Bandung. 